\title{
Cyclone "MOHASEN" monitored using remote sensing technology
}

\author{
Suraiya Begum ${ }^{1,3}$, Mehrun Nessa ${ }^{2,3}$, Md. Saheb Ali ${ }^{2,3}$ \\ ${ }^{1}$ Regional Remote Sensing Centre (RRSC), Division ,Dhaka, Bangladesh \\ ${ }^{2}$ Atmospheric Research Division, Dhaka, Bangladesh \\ ${ }^{3}$ Bangladesh Space Research and Remote Sensing Organization, Agargaon, Dhaka, Bangladesh

\section{Email address:} \\ bsuraiya89@yahoo.com(S. Begum), suraiyabegum@rocketmail.com(S. Begum), mehrun_nessa@yahoo.com(M. Nessa)
}

\section{To cite this article:}

Suraiya Begum, Mehrun Nessa, Md. Saheb Ali. Cyclone "MOHASEN" Monitored Using Remote Sensing Technology. International Journal of Environmental Monitoring and Analysis. Vol. 1, No. 3, 2013, pp. 95-98. doi: 10.11648/j.ijema.20130103.14

\begin{abstract}
Cyclones occur inBangladesh almost every year andloseslives and properties whichhamper the sustainable development.They are usually formed in the deep seas and hence their studiesare very difficult. Space Technology provides valuable information about them and helpful for such conducts. Meteorological satellites are the main sources of information which allow monitoring the formation, development and movement of tropical cyclones. Methodology suggested by D'Vorak is very useful for tropical cyclone analysis which provides cyclone intensity called T-number and corresponding maximum sustained wind speed of the cyclone as well as the pressure around it.Cyclone MOHASEN was initially formed as a low in the Bay near Andaman's at the $2^{\text {nd }}$ week of May, 2013 and gradually intensified into Cyclonic storm MOHASEN afterwards. It was moving towards north -west direction at the primary stage very slowly and north -westward rapidly in the final stagetowards Bangladeshcoast. It was gradually intensified but not significantly. The pick was found on 15 May,2013. The intensity i.e, the T number of the cyclone was then found as T 2.5 / T3.0 . The corresponding max sustained wind speed was then $70-80 \mathrm{~km} . / \mathrm{hr}$. Cyclone MOHASEN then made landfall on Bangladesh coast near Borguna -Potuakhali on 16 May,2013 at the morning. It was weakened after hitting the land due to frictional force and battering the area with heavy rain and strong winds. It made the wave propagated over 6 to $7 \mathrm{ft}$ high . The formation, duration and evolution of the cyclone was monitored at SPARRSO ground station mainly using the hourly basis data obtained from MTSAT-1 and FY-2D/E Geo-stationary satellites. The imageries were analyzed using Vimsat, Gmsoft and Dvorak's algorithm to find out the location, intensification and to observe the movement of the cyclone necessary for early warning and preparedness towards sustainable development of the country. In this paper, monitoring of Cyclone "MOASEN", formed in the West part of Bay of Bengal North Indian Oceanin 2013, has been conducted through remote sensing technology.
\end{abstract}

Keywords: Advance Warning, Intensity, Monitored, Remote Sensing, Sustainable Development

\section{Introduction}

Bangladesh is one of the most disastrous countries in the world. Cyclone is the most common and destructive one among them. It usually occurs during pre-monsoon (March -May) and post-monsoon (Oct-Nov) seasons. Some of them are turned into severe up to super cyclones. It is a tropical storm or tropical disturbance or atmospheric turbulence involving circular motion of winds [1, 2]. Cyclones cause damage to crops that reduces the rice production. It occurs in Bangladesh almost every year andlosses lives and properties which hampers the sustainable development.Man cann't stop but can mitigate the losses due to them adapting the preparedness and safety timely. Advance warning is very essential for that and Space Technology/Remote Sensing plays an important role in this regard. SPARRSO monitors all natural calamities like depression,cyclone formed in the Bay of Bengal and North Indian Ocean regularly since 1980 using Remote Sensing \& GIS and disseminate early warning on time. It helps the disaster management and preparedness program of the Govt. for saving lives and properties towards the sustainable development of the country.

Cyclone 'MOHASEN' named by UN/ESCAP was the tropical cyclone of 2013 that hit Bangladesh. We, the scientists of SPARRSO made continuous observation on it using remote sensing technology. The images received at 
SPARRSO ground station from latest Geo Stationary satellites FY-2D/E \& MTSAT-1 were processed and analyzed to monitor the formation, cloud system, and evolution of cyclone on real time basis. The observation was conducted to identify the nature and track of cyclone in order to find out the necessary information regarding early warning and preparedness as well as for this study.

\section{Objectives}

The objective of the study can be summarized as follows:

To monitor the formation and evolution of cloud systems ; to find out the intensity of the cyclone; to study its movement and behavior ; to identify and track of the cyclone formed in the Bay; to provide early warning that would useful for disaster management and preparedness program of GoB towards sustainable development.

\section{Data Used}

This study was conducted mainly using the remotely sensed data obtained from Geostationary Satellites received at SPARRSO Ground station. The hourly data of FY-2D/E and MTSAT-1 satellites were used to monitor the cyclone and the full disk MTSAT-1 data were used to extract its different parameters like the intensity of cyclone. Data from Special Bulletin for cyclones provided by Bangladesh Meteorological Dept. and information from website were used to validate the space based data received at SPARRSO ground station.

\section{Methodology}

The methodology of the study included Remote Sensing Techniqueand D'Vorak method. We processed and analyzed the images received from the FY-2 \& MTSAT-1 satellites at SPARRSO Ground station using Vimsat \& Gmsoft in every hour. Data received from MTSAT-1 were made contrast of Channel 2 and 4 with the help of its modulefor analysis. These satellite images were enhanced to identify clearly the cloud system, its coverage and cloud dense overcast (CDO) to find out the center of cyclone[2, 3]. The location of cyclone center and its distances from important places were extracted using the existing software (Vimsat and Gmsoft) installed with FY-2D/E ground station at SPARRSO. The Full Disk data of MTSAT-1 and D'Vorak method were processed and analyzed to find out the intensity ( $\mathrm{T}$-number) of the cyclone, pressure and the corresponding maximum sustained wind speed around the cyclone center.

\section{Monitoring}

Cyclone MOHASEN was formed in the Bay of Bengal initially as a low. It then developed day by day and turned into a depression on 10 May, 2013. The Depression over south-east Bay and adjoining area moved slightly northward and intensifing.It was centered at lat $5.5^{\circ} \mathrm{N}$ and Long $920^{\circ}$ E on same day and was moving towards north-west direction very slowly under the influence of a subtropical ridge of high pressure before its further development. The depression was turned into a deep depression almost over the same area on 11May, 2013 and intensified into cyclonic storm MOHASEN afterwards. The center of the cyclone was at lat $10.4^{\circ} \mathrm{N}$ and Long $86.7^{\circ} \mathrm{E}$ on 12 May at 17:31 BDT(Fig-1).

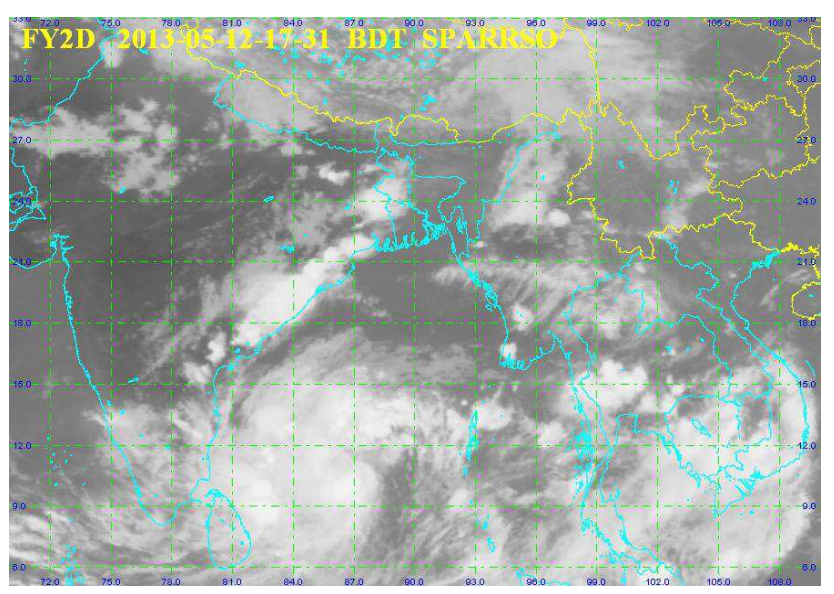

Fig-1. FY-2D Satellite image of May 12, 2013at 17:31 BDT

It was then located $1215 \mathrm{~km}$ apart from Mongla Port, $1290 \mathrm{~km}$. apart from Cox Bazar and $1345 \mathrm{~km}$. apart from Chittagong port. At that time, the intensity of the cyclone was observed as T1.5.The monitoring was conducted every hourly. Within next couple of days, Cyclone MOHASEN intensified further and the pick was found on 15May,2013.It changed its direction slightly towards north and north-west direction and started moving towards Bangladesh coast rapidly.

Continuous observation ( Fig-2,3,4 ) was made using the satellite data and modulie at SPARRSO Ground station to study its movement and behavior. MOHASEN then made landfall near Barguna-Potuakhali ofBangladesh coast battering the area with heavy rain and strong winds (Fig -5). The Track of cyclone MOHASEN is shown in Fig-6.

It was observed that the cyclone became weak after hitting the coastal area of Bangladesh due to frictional force associated with it. At that time the intensity of the cyclone was found as T3.0 and the corresponding max sustained wind speed was observed as $70-80 \mathrm{~km} / \mathrm{hr}$. 


\section{Results}

The results of monitoring areshown in Table-1.

Table-1. Data extracted from SPARRSO Satellite Ground Station

\begin{tabular}{|c|c|c|c|c|c|c|c|c|}
\hline \multirow[b]{2}{*}{ Date } & \multirow{2}{*}{$\begin{array}{l}\text { Time } \\
\text { BDT }\end{array}$} & \multicolumn{2}{|c|}{ Center/Location } & \multirow{2}{*}{$\begin{array}{l}\text { Intensity } \\
\text { T- no. }\end{array}$} & \multirow{2}{*}{$\begin{array}{c}\text { Corresponding } \\
\text { wind speed }\end{array}$} & \multicolumn{3}{|c|}{ Distance } \\
\hline & & Lat & Long & & & $\begin{array}{c}\text { Chittagong } \\
\text { port }\end{array}$ & Cox'Bazar & $\begin{array}{c}\text { Mongla } \\
\text { port }\end{array}$ \\
\hline \multirow{3}{*}{$12 / 05 / 13$} & $08: 31$ & 08.5 & 87.0 & 1.0 & & 1439 & 1323 & 1405 \\
\hline & & & & & & & & \\
\hline & $15: 04$ & 09.9 & 86.7 & 1.0 & $10-20$ & 1394 & 1301 & 1325 \\
\hline \multirow{4}{*}{$13 / 05 / 13$} & $09: 34$ & 12.5 & 84.3 & 1.5 & $10-20$ & 1345 & 1290 & 1215 \\
\hline & $13: 04$ & 12.7 & 84.2 & 1.5 & $20-30$ & 1314 & 1256 & 1148 \\
\hline & $14: 31$ & 12.5 & 84.9 & 1.5 & $20-30$ & 1280 & 1202 & 1183 \\
\hline & $15: 31$ & 12.6 & 84.7 & 1.5 & $30-40$ & 1273 & 1192 & 1170 \\
\hline \multirow{7}{*}{$14 / 05 / 13$} & $08: 31$ & 14.6 & 84.8 & 2.0 & $50-60$ & 1131 & 1001 & 1085 \\
\hline & $14: 31$ & 14.8 & 84.9 & 2.0 & $50-60$ & 1076 & 1019 & 959 \\
\hline & $15: 31$ & 15.0 & 84.8 & 2.0 & $50-60$ & 1059 & 997 & 928 \\
\hline & $16: 31$ & 15.0 & 85.4 & 2.5 & $60-70$ & 1036 & 970 & 911 \\
\hline & $17: 31$ & 15.0 & 85.0 & 2.5 & $60-70$ & 1030 & 965 & 906 \\
\hline & $18: 31$ & 15.4 & 84.8 & 2.5 & $60-70$ & 1078 & 1017 & 942 \\
\hline & $19: 31$ & 15.7 & 85.1 & 3.0 & $70-80$ & 990 & 955 & 870 \\
\hline \multirow{5}{*}{$15 / 05 / 13$} & $07: 31$ & 17.5 & 86.1 & 3.0 & $70-80$ & 780 & 751 & 652 \\
\hline & $13: 31$ & 19.2 & 87.9 & 3.0 & $70-80$ & 510 & 492 & 375 \\
\hline & $15: 01$ & 19.6 & 88.2 & 2.5 & $60-70$ & 463 & 426 & 325 \\
\hline & $18: 31$ & 19.9 & 88.4 & 3.0 & $70-80$ & 440 & 409 & 290 \\
\hline & $21: 31$ & 20.0 & 88.6 & 3.0 & $70-80$ & 417 & 380 & 275 \\
\hline \multirow{2}{*}{$16 / 05 / 13$} & 02:04 & 20.1 & 89.6 & 3.0 & $70-80$ & 373 & 335 & 250 \\
\hline & $07: 31$ & 22.3 & 89.8 & 3.0 & $70-80$ & & & \\
\hline
\end{tabular}

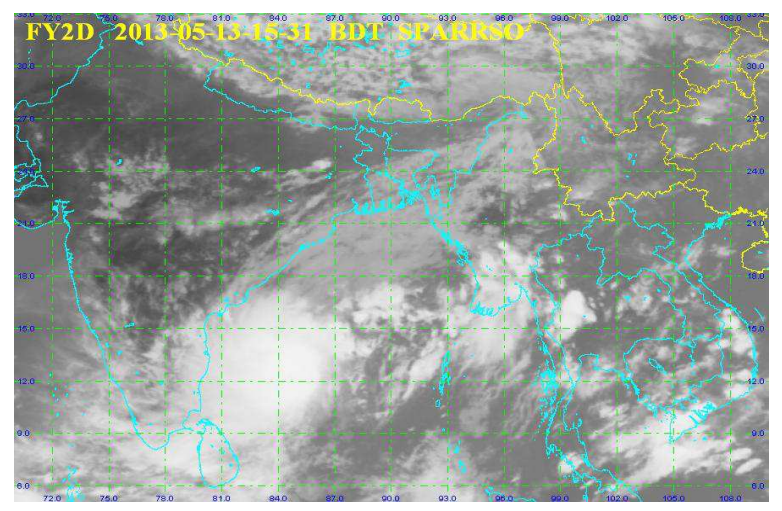

Fig-2. FY-2D Satellite image of May 13,2013 at 15:31 BDT 


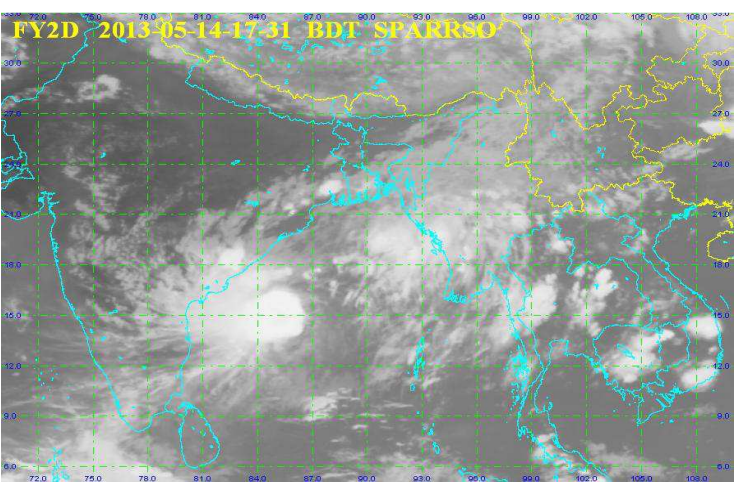

Fig-3. FY-2D Satellite image of May14,2013at 17:31 BDT

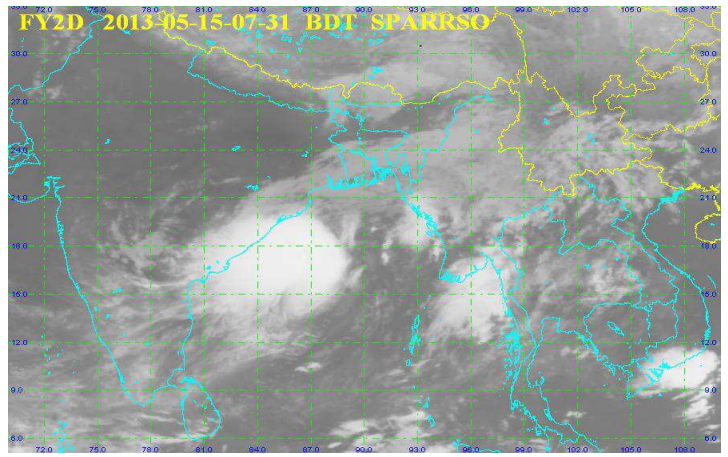

Fig-4. FY-2D Satellite image of May15,2013at 07:31 BDT

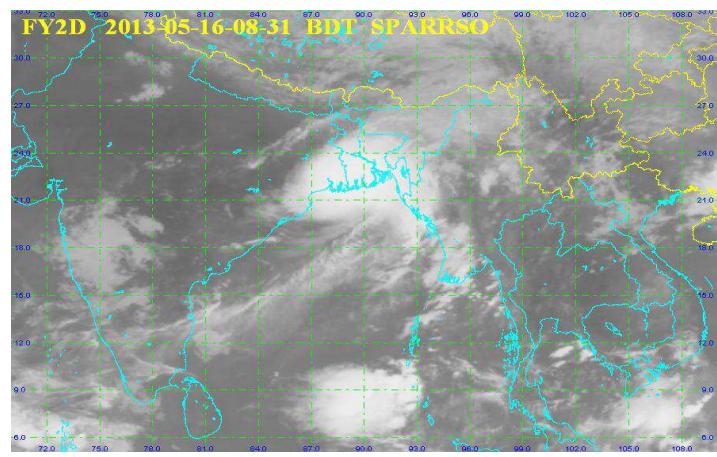

Fig-5. FY-2D Satellite image of May 16,2013 at 08:31 BDT

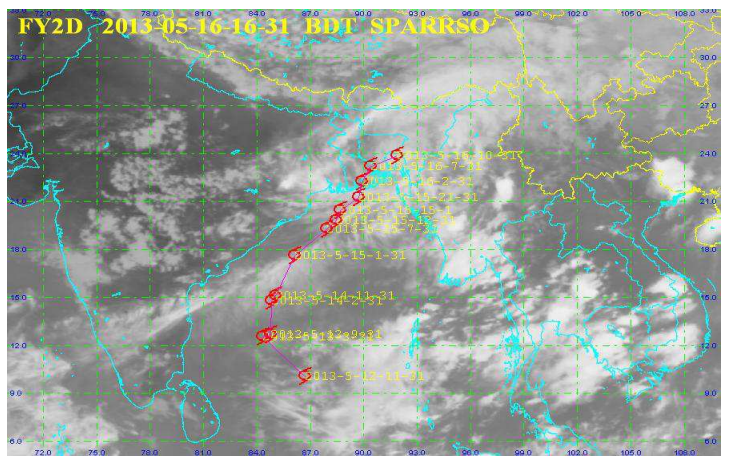

Fig-6. Track of cyclone MOHASEN shown in FY-2D Satellite image

\section{Conclusion}

Cyclone MOHASEN was monitored on real time basis using remote sensing data received at SPARRSO Ground station and applying space technology. The satellite data were processed and analyzed to gether information necessary for advance warning. The analysis showed that the cyclone was initially formed as a low in the Bay near Andaman's at the $2^{\text {nd }}$ week of May, 2013 and gradually intensified into Cyclonic storm MOHASEN afterwards. It was moving towards north -west direction at the primary stage very slowly and towards north-westdirection rapidly in developing stage. It was gradually intensified but not significantly .The pick was found on 15 May, 2013. The intensity i.e, the $\mathrm{T}$ number of the cyclone was then found as

T 2.5 / T3.0 .The corresponding max sustained wind speed was then $(70-80) \mathrm{km} . / \mathrm{hr}$. Cyclone MOHASEN then made landfall on Bangladeshnear Borguna-Potuakhali on 16 May, 2013 at the morning at 08:31 BDT. It became weaker when hitthe land due tofrictional force and battering the area with heavy rain and strong winds. It made the wave propagated over 6 to $7 \mathrm{ft}$ high $[4,5$, and 6]. Timely preparedness is necessary to reduce the losses due to any disaster/cyclone. Space technology contributes a lot in this regard. The weather report and early warning we provide on time using space technology helped the Government and its organizations to take necessary steps and preparedness in the respective areas (pre and post disaster management program of the Government) towards the sustainable development of the country. More study is needed to find out the cyclone path in advance, the behavior of cyclone formed in Bay of Bengaland to characterize them.

\section{References}

[1] Choudhury A.M., and Anwar Ali ,1974- Prediction of maximum wind speed in cyclones in the Bay of Bengal A preliminary investigation. Nuclear Science and Application, 7, 109-113.

[2] Choudhury A.M., Quadir D.A. and Nessa,M , 1998- ISSN 1560-201X. Journal of Remote Sensing and Environment, 1998, Vol. 2, 51-69.

[3] Quadir D.A., 1994-An Experiment on the Evolution of Tropical Cyclone using a Numerical Model Special Bulletin of BMD Daily weather forecast of MediaNews papersWebsite (Internet source) 